4

\title{
«YO NO SÉ POR QUÉ SERÁ QUE ELLOS NO QUIEREN HABLAR LA IDIOMA"
}

NOTAS DE CAMPO SOBRE LA SITUACIÓN SOCIOLINGÜÍSTICA DE LA LENGUA QOM EN COLONIA ABORIGEN, CHACO

Agustina Paredes 


\title{
RESUMEN
}

En este artículo se reflexiona sobre la situación sociolingüística de la población autorreconocida como qom asentada en Colonia Aborigen Chaco. El trabajo forma parte del comienzo de una investigación doctoral que continúa un trabajo de tesina de licenciatura en Letras. Particularmente, se hace foco en los ámbitos de uso de las lenguas para indagar en la vitalidad de la lengua indígena, a partir de las representaciones de los hablantes como también de las prácticas comunicativas observadas. El artículo se basa e ilustra a partir de las entrevistas realizadas durante el trabajo de campo llevado a cabo en enero de 2019.

\begin{abstract}
In this article we reflect on the sociolinguistic situation of the self-recognized population as settled in Colonia Aborigen Chaco. The work is part of the beginning of a doctoral research that continues with a thesis work of a degree in Letters. Particularly, it focuses on the areas of use of languages to investigate the vitality of the indigenous language, from the representations of the speakers as well as the communicative practices observed. The article is based on and illustrated from the interviews conducted during the fieldwork carried out in January 2019.
\end{abstract}

\section{PALABRAS CLAVE}

$>$ lengua indígena qom

$>$ desplazamiento lingüístico

$>$ estrategias de revitalización

\section{KEYYWORDS}

$>$ qom indigenous language

$>$ linguistic displacement

$>$ revitalization strategies 


\section{INTRODUCCIÓN}

El objetivo de este artículo es presentar algunos datos cualitativos obtenidos hasta el momento con respecto a la situación sociolingüística de la lengua qom en Colonia Aborigen, Chaco. Este somero relevamiento es parte del comienzo de mi investigación doctoral en la que me propongo estudiar la situación sociolingüística en la comunidad qom asentada en Colonia Aborigen, Chaco desde la perspectiva de la lingüística antropológica y, por ende, sobre la base del trabajo de campo.

La lengua qom pertenece a la familia lingüística guaycurú (qom, mocoví y pilagá) que es autóctona de la Región Chaqueña y es denominada por sus hablantes como qom l'aqtaqa (el idioma de los qom). La autodenominación qom significa en su lengua "gente» y la palabra toba, cuyo significado en lengua guaraní es frente ancha se utilizó para nombrarlos por la particular forma en que se afeitaban el cabello.

Actualmente, dicha lengua se habla en Chaco, Formosa, Salta, Buenos Aires y Santa Fe. Si bien presenta una denominación generalizada, no puede ser pensada como una unidad homogénea porque se compone por un conglomerado de variedades dialectales marcadas por notables diferencias fonológicas y léxicas (Messineo, 2003). De acuerdo con el Censo Nacional de Población llevado a cabo en el año 2010, en todo el país hay un total de 126.967 indígenas qom.

Tradicionalmente, los qom:

Vivían en bandas bilaterales nómades, compuestas por un número variable de familias extensas que se dedicaban a la caza y a la recolección en la parte central, meridional y austral del Gran Chaco. (Miller, 1979 en Hecht 2011: 4)

Avanzado ya el siglo XIX y a partir de entonces (de los años ochenta) comenzaron a ser conquistados y sometidos. Como consecuencia, transformaron su vida al sedentarismo e iniciaron un proceso de desterritorialización; muchas familias abandonaron sus tierras originarias y migraron hacia diversos centros urbanos, chaqueños y en otras ciudades del país como Rosario, Buenos Aires y La Plata.

En términos de educación bilingüe y legislación, la provincia de Chaco se destaca por ser pionera en el reconocimiento indígena; sus propias comunidades han sido quienes generaron la iniciativa para visibilizar y efectuar los derechos 
básicos de los qom, wichí y moqoit'. Dentro del repertorio de leyes, la Ley Provincial $N^{\circ} 6604$ (2010) se destaca, ya que declara como:

Lenguas oficiales de la Provincia , además del castellano-español, a las de los pueblos preexistentes qom, moqoit y wichí y ordena la creación del Consejo Provincial Asesor de Lenguas Indígenas (en el que podrán participar miembros de cada comunidad originaria) para desarrollar tareas técnico-políticas y cumplir con lo establecido. (Artículo 1:1)

Al definirlas como tales les permite «a los ciudadanos de los tres pueblos usar estas lenguas en los distintos ámbitos del Estado Provincial» (ya no solamente en el ámbito educativo). (Artículo 4, pp.1). Al igual que la Ley Nº 6691 de Educación General de la Provincia; con ella se pone al frente de las escuelas a dirigentes y maestros indígenas diplomados, y a un consejo de ancianos. No obstante, a pesar de la promoción legislativa, persiste el desplazamiento lingüístico.

De acuerdo con estudios realizados hasta el momento el desplazamiento lingüístico es más característico en contextos urbanos y en las generaciones de jóvenes. En el año 2003, Messineo aseguraba: «El contacto con la sociedad hispanohablante y el abandono de los lazos intergeneracionales y parentales contribuyen cada vez más a la pérdida de la lengua vernácula en las generaciones más jóvenes» (Messineo, 2003:21).

En el 2005, Censabella al observar la amplia variedad de situaciones que atraviesan las lenguas indígenas asentaba que:

En los ámbitos urbanos o semi-urbanos, suele aprenderse la lengua de la sociedad dominante como primera, adquiriendo simultáneamente diferentes niveles de competencia comunicativa en la lengua vernácula según diversos factores, especialmente la actitud de los padres frente a la misma. Con respecto a la variable edad -en la mayoría de los casos- a mayor edad, mayor competencia comunicativa y lingüística, a menor edad, menor competencia comunicativa y lingüística. (Censabella, 2005:2-3)

\footnotetext{
${ }^{1}$ No pueden dejar de mencionarse las siguientes leyes provinciales: Ley del Aborigen Chaqueño $N^{\circ} 3258$, el Decreto N²75, Ley N 970, Ley N6604, Ley de Educación N 6691, Ley Provincial de Educación Pública de Gestión Comunitaria Bilingüe Intercultural Indígena No 7446.
} 
Años más tarde, Hecht (2009) analiza el caso de la comunidad del barrio Derqui de Buenos Aires (Argentina). La autora destaca que sus miembros son migrantes indígenas bilingües y evidencian signos de un proceso de desplazamiento de la lengua qom por el español en la mayoría de las situaciones comunicativas en las que participan los niños.

En síntesis, aún con sus particularidades, estos diagnósticos sociolingüísticos evidencian el proceso paulatino de desplazamiento que está sufriendo esta lengua en los distintos asentamientos donde reside su población.

\section{COLONIA ABORIGEN CHACO}

La Colonia se ubica en la zona central de la provincia, entre los departamentos 25 de mayo y Quitilipi (a siete kilómetros al sur de las ciudades de Quitilipi y Machagai). El límite norte de la Colonia corre paralelo a la ruta Nacional $N^{\circ} 16$ que une la ciudad de Resistencia con Presidencia Roque Sáenz Peña. La longitud del territorio en dirección este/oeste es de aproximadamente 30 km y en dirección norte/sur es de 7,5 km.

La reserva indígena presenta 20.000 hectáreas (18.000 en jurisdicción de Machagai y 2.000 de Quitilipi) distribuidas en los Lotes 38, 39 y 40 y tiene su origen en 1911, cuando fue fundada como Reducción Indígena de Napalpí (que en qom significa lugar de los muertos). La finalidad de la reducción era, en términos generales, educar y disciplinar a los indígenas y asimilarlos a la masa general del pueblo e incorporarlos como mano de obra barata en azucareras, obrajes y algodoneras. Pero los indígenas eran explotados y maltratados. En 1924 decidieron resistirse, pero sin ánimos de sublevación ni ataques; y ocurrió la masacre y no la lucha, porque fue una matanza en la que solo murieron indígenas qom y mocovíes, y no soldados. Por eso, el lugar pasó a llamarse Colonia La Matanza. Más tarde llevó otras denominaciones como Colonia Chaco (como muestra de ocultamiento). Actualmente, un cartel a la vera de la ruta $\mathrm{N}^{\circ} 16$ indica el ingreso a Colonia Aborigen Chaco.

En Colonia Aborigen se observa un pueblo central y veinte sectores rurales. Desde la ruta $\mathrm{N}^{\circ} 16$ se ingresa a la Colonia por un camino de tierra enripiado de 7 km de extensión. La comunidad tiene un total de 5000 habitantes: 90\% qom, $10 \%$ moqoit. En el pueblo central hay cerca de 2000 residentes, mientras que cada sector cuenta con cincuenta familias y doscientos cincuenta habitantes. Uno 
de estos sectores pertenece a la etnia mocoví. La Colonia es reconocida como uno de los mayores asentamientos indígenas de la Argentina.

Vale destacar que sus tierras son de uso comunitario, ya sea para la explotación agrícola o ganadera. Sus habitantes viven, principalmente, gracias a planes sociales de asistencia a la pobreza y el desempleo (que otorgan el gobierno nacional y provincial) y aportes del Estado como el Plan Familia y pensiones varias.

En el centro de la Colonia se encuentra una iglesia católica y otra evangélica, la delegación del Instituto del Aborigen Chaqueño (IDACH), un destacamento policial, las oficinas del Registro Civil y el edificio de la Asociación Comunitaria. También, funciona una radio de Frecuencia Modulada y, al lado del ella se halla el salón de artesanías El cantaro na'acoña. Cada sector cuenta con su propio jardín, escuela e iglesia y salón comunitario. Incluso, algunos tienen sala de primeros auxilios.

En el año 2017 tuve un primer acercamiento al referente empírico, ya que realicé un trabajo de campo para mi investigación de la tesina de Licenciatura en Letras (FHUC-UNL). El estudio realizado en aquel momento puso de manifiesto el desplazamiento lingüístico de la lengua indígena en favor del español, y las principales causas relevadas fueron: el contacto de los jóvenes indígenas con los no indígenas, la vida en la urbanidad o las grandes distancias que los aíslan, los problemas con las adicciones, la falta de sentimiento identitario indígena y la imposición del uso del español por parte del contexto de comunicación socio-étnico. Sin embargo, ante esta realidad, fuertemente marcada por procesos históricos de sometimiento y represión, hay lugar para espacios de resistencia. Es decir, cobran fuerza las estrategias de resistencia etnolingüísticas: las acciones tendientes a recuperar los espacios funcionales de uso que una lengua ha perdido por diversas razones sociales, culturales y económicas. Aquí es fundamental destacar el valor determinante que desde el seno de la comunidad le adjudican a la educación, para ellos «la única alternativa es estudiar. Todo el pueblo indígena tiene que estudiar». En las escuelas, por ejemplo, procuran realizar los saludos y las bendiciones de los alimentos en lengua qom. En los espacios del culto, cantan y leen también en lengua vernácula. Igualmente, en la radio local, dan lugar a un programa religioso en ambas lenguas, con el fin de que, al escuchar la emisión en qom, la gente se anime a participar (el locutor asegura que dicha estrategia funciona). 
Frente a la situación expuesta comenzaron a surgir nuevos interrogantes que pretenden abordarse en la instancia actual de inicio de mi investigación de doctorado. Así, me propongo abordar cuestiones, tales como: ¿En qué ámbitos de usos, entre quiénes, para qué fines y hablando de qué temas utilizan los qom alternativamente el qom o el español?, ¿En qué medida la población está comprometida con la revitalización de su lengua?, ¿Qué actividades pueden llevarse a cabo con personas de distintos grupos etarios (porque revitalizar no solo debe vincularse con los niños) cuyo eje sea la lengua indígena y la adquisición de habilidades comunicativas significativas?

\section{METODOLOGÍA Y MARCO TEÓRICO}

La investigación tiene carácter etnográfico: se parte de un proceso de observación participante basado en la experiencia y en la exploración. De acuerdo con Duranti, "La etnografía es la descripción escrita de la organización social, las actividades, los recursos simbólicos y materiales, y las prácticas interpretativas que caracterizan a un grupo particular de individuo» (Duranti, 1997: 126).

Para poder llevar a cabo una descripción de este tipo es necesario participar directa y prolongadamente en la vida social de la comunidad sobre la cual se desea investigar. Igualmente, resulta necesario poder distanciarse lo suficiente para conseguir un grado aceptable de objetividad en la descripción (el etnógrafo debe controlar el propio juicio de valor) pero, al mismo tiempo, poder tener empatía con los miembros del grupo

Según Guber (2001) la comprensión a la que debe llegar la descripción de un pueblo para ser denominada trabajo etnográfico es la que corresponde a la comprensión de los fenómenos sociales desde la perspectiva de sus miembros, entendidos como actores, agentes o sujetos sociales. La autora destaca que el significado de lo observado no tiene sentido si es aislado del contexto en el que se ha considerado. Por tanto, es fundamental ubicar los fenómenos producidos por el contacto de lenguas en sus contextos sociales. Solo así podrán comprenderse los motivos por los cuales el grupo observado privilegia una u otra lengua para su comunicación. 
En consecuencia, el relevamiento de datos en el campo se realiza a partir de metodología cualitativa, para la cual la obtención de datos no es cuantificable, es decir, no pueden ser sometidos a un tratamiento numérico, sino que poseen un valor propiamente contextual y permiten analizar la realidad subjetiva. Dentro de este tipo de metodología se encuentran la observación participante, la participación en eventos y situaciones de la vida cotidiana, las entrevistas y charlas informales con miembros de la etnia qom y con responsables de instituciones de diversos espacios, como la escuela, los centros comunitarios, las iglesias y centros de salud. Las entrevistas llevadas a cabo en la Colonia son del tipo semidirigidas, las cuales constan de una interacción verbal flexible, de un modo similar al de una conversación. La ventaja de este tipo de entrevista es que, si bien los entrevistados responden a ciertas preguntas concretas, igualmente tienen la posibilidad de explayarse en el tema y expresarse libremente sobre las cuestiones que prefieran. El objetivo de las entrevistas es estudiar la situación sociolingüística de la lengua qom, observando y documentando espacios de uso de las lenguas (español y qom), considerando las variables de género, edad, roles y espacios sociales, como así también identificando las causas que motivan la elección, transformación, el mantenimiento o la sustitución de la lengua indígena, así como los usos combinados de ambas lenguas, entre otros.

Sobre la base de lo arriba expuesto, este artículo se inserta en el campo de la Antropología Lingüística. Además, incorpora los desarrollos de la lingüística de contacto (Aikhenvald y Dixon 2006; Appel y Muysken 1987; Filipović 1986; Hymes 1971; Thomason y Kaufman 1991; Weinreich 1994) y se nutre de una perspectiva sociolingüística (Gumperz y Hymes, 1972; Romaine, 1996).

La Antropología Lingüística es un campo interdisciplinario que parte de la etnografía para estudiar el lenguaje en cuanto recurso cultural y el habla cotidiana en cuanto práctica social (Duranti 2000, 2002). Se habla de un campo interdisciplinario porque se desarrolla sobre métodos que pertenecen a otras disciplinas, especialmente la antropología y la lingüística, a fin de proporcionar una comprensión de los variados aspectos del lenguaje, como un sistema de comunicación que permite las representaciones entre los individuos y con el individuo mismo.

Los antropólogos lingüistas ven a los hablantes como actores sociales. Su interés no radica solo en el uso del lenguaje, sino en: «Su visión del lenguaje 
como un conjunto de estrategias simbólicas que forman parte del tejido social y de la representación individual de mundos posibles y reales» (Duranti, 2000: 22).

Es decir, consideran al lenguaje como condición y resultado de la interacción social, como una práctica social e histórica; y a los hablantes como agentes que actúan sobre las lenguas resignificando las formas en función de contextos dinámicos.

\section{LO QUE LA GENTE DICE SOBRE LAS LENGUAS}

A continuación, se exponen las representaciones de los entrevistados en el trabajo de campo, llevado a cabo durante la última semana de enero del 2019, frente al avance el español y al lugar que la lengua posee en el ámbito íntimo de la familia y en la Colonia en general, es decir, en sus distintos ámbitos de uso. Además, se observa lo que la lengua representa en la esfera de lo simbólico.

Se entrevistaron directamente a once (11) miembros de la comunidad qom de entre 27 y 70 años. Algunos de ellos habitantes del Lote 38 de la Colonia y otros del 39. Los comentarios dados por la mayoría evidencian que son conscientes del proceso de desplazamiento de la lengua, especialmente por parte de las generaciones jóvenes que se niegan a usarla: «El que tiene de treinta años para abajo habla el español», «Nosotros profundizamos y queremos seguir aprendiendo el español y la lengua nuestra queda como segundo espacio y eso nos afecta, y la dejamos pero no porque la queremos dejar», "Yo no sé por qué será que ellos no quieren hablar la idioma», "A los jóvenes les llega la discriminación y no la aguantan», «Los chicos no hablan la idioma, parece que tienen miedo que los discriminen».

Algunas personas dicen sentirse responsables de que esto ocurra por interrumpir la transmisión intergeneracional de la lengua: «A mis hijos les hablo en español porque es más afectivo», "Nuestro descuido principal es que no lo hablamos a los chicos», "Nosotros dejamos, hoy en día nos arrepentimos, porque vamos a volver para atrás». Otras, en cambio, aseguran que en el ámbito familiar a sus hijos les hablan en qom: "Tenés que enseñarles a los chiquitos, a una criatura a un bebé le tenés que hablar, porque cuando sea grande ya cuesta para hablar, nosotros hablamos en qom, (...) yo les enseño a mis nietos». Este último caso es característico de integrantes del Lote $N^{\circ} 38$; allí aseguran que la lengua «No 
se está perdiendo»; "Los chistes que nosotros hacemos cuando nos juntamos, los que nos acordamos, los seguimos haciendo en qom», «En nuestra zona no, generalmente mantenemos, los chicos hablan la lengua todavía, la entienden. En la parte nuestra se conserva. No sé si dejar, yo creo que.... más bien lo que yo veo en nuestra zona, en otras zonas sí prácticamente se va perdiendo, pero en nuestra zona no. Generalmente mantenemos, por ejemplo, en el caso acá, si ustedes hablan la lengua mía estaríamos hablando en el dialecto. Pero sí en otros lotes se está dejando».

Muchos coinciden en que la lengua ha ido dejando de hablarse por la discriminación que han sentido a lo largo de la historia: «Los jóvenes se avergüenzan por la falta de escritura y discriminación», «Piensan que hablar su lengua es retroceder en el tiempo». Aseguran que, actualmente, muchos ancianos no lo hacen por la forma en que se les negó su lengua cuando eran más jóvenes: «Los más viejos no se animan a hablar en qom por vergüenza. En el banco, no se pueden expresar con libertad porque los hacen sentir como si fueran de otro planeta», «Cuando vamos al supermercado mi mamá no se anima a usar el dialecto, sin embargo, yo le hablo para captar la atención de la gente de alrededor».

Otro factor que mencionan, principalmente los ancianos, en este proceso de desplazamiento es la influencia de la escuela antes de la llegada de la E.I.B: «Los ancianos nos inculcaron no perder la idioma. Después, con la civilización, con las escuelas, se empezó a perder». "A mis hijos les hablo en qom, algo entienden, pero están civilizados en lengua española», "En los tiempos que, vamos a decir que ya pasaron, la escuela no quería, los mismos maestros iban e interrumpían a los chicos, no los dejaban usar el dialecto».

Sobre la base de las reflexiones expuestas puede decirse que, las personas refieren que el español goza de un mayor uso en las relaciones comunicativas y la lengua qom se usa en menor medida. Desde el seno de la comunidad existe la preocupación por realzar el prestigio de la lengua vernácula. Ejemplo claro de esto, es la obligación y responsabilidad que sienten los abuelos por transmitir la lengua a sus nietos, sobre todo en los primeros años; o el interés de los mismos adultos por aprender la lengua qom: «Yo recién ahora la quiero aprender, porque la entiendo, porque procuro, si vos procuras aprendes, ahora si no procuras, fuiste. Yo le hablo algunas palabras, pero hasta ahí nomás. Ahora, mi hija aqueIla, no y mi esposa tampoco.» Al igual que las celebraciones del culto que son 
impartidas en ambas lenguas, e incluso se utiliza una Biblia qom. También, se busca revitalizar la lengua a través de la radio: su locutor realiza un programa religioso en español y qom. El mismo asegura que poco a poco las personas se han ido animando a participar del programa.

Simbólicamente hablando, los entrevistados manifestaron el interés por mantener la lengua porque es «su» lengua y es parte de su identidad. De hecho, algunos coinciden que no puede hablarse únicamente de transmitir o perder la lengua, sino que la cuestión es mucho más compleja, ya que la lengua forma parte de un estilo de vida, de una cultura, de una forma de pensar; de una cosmovisión. Es decir, si se habla de una lengua que se desplaza/se pierde, se habla en realidad de una cultura que sufre tal proceso. Tal como sostiene Hamel (1995):

«No se trata simplemente de que una lengua «desplace» a la otra (...), sino de procesos a través de los cuales los actores bilingües van transformando sus usos y repertorios en todas sus dimensiones.» (p. 81)

Frente a la pregunta ¿Qué cree que se podría hacer para mantener la lengua?, la mayoría coincide en que deben «buscar la forma de inculcarla diariamente» $y$ «enseñarla desde chiquitos». Pero, ¿Qué hacer con el grupo de jóvenes que ya no son «chiquitos»? ¿Qué tipo de estrategias deben generarse? Los entrevistados dijeron no saberlo. Se espera que con el avance de esta investigación pueda atenderse y encontrar posibles «soluciones» para este vacío tan grande que aún queda.

\section{LO QUE LA GENTE HACE CON LAS LENGUAS}

Más allá de lo referido en las entrevistas y a partir de lo observado en el trabajo de campo, puede decirse que los principales espacios de uso de la lengua qom son el hogar, el culto y las reuniones entre amigos (saludos y chistes). El grupo etario que más la usa en su cotidianeidad es el de los ancianos y adultos. Los ancianos son los que se muestran más comprometidos con la transmisión intergeneracional de la lengua; ellos, en su mayoría, tienen al qom como primera lengua y usan el español solo de ser necesario. Los adultos, por su parte, en ge- 
neral tienen como primera lengua al español, pero también hablan el qom. Los hombres, en particular, en sus encuentros sociales suelen contar chistes en qom.

Es decir, estamos frente a un caso de bilingüismo, cuyo grado varía según la educación y la actividad social/laboral que realicen. Se ha tenido muy poco contacto con los jóvenes y niños ${ }^{2}$ en este último trabajo de campo, pero de acuerdo con lo investigado en el 2017, y según cuentan los entrevistados, ellos son casi todos monolingües en español, aunque hay casos de niños, que viven con sus abuelos o los frecuentan, que hablan fluidamente el qom y otros que, si bien no lo hablan, lo entienden. En el Lote 38 me encontré con niños que interactuaban en qom con sus abuelos $y$, de hecho, me enseñaron algunas palabras.

En el sector educativo, los directivos aseguran que los estudiantes no presentan interés por la lengua indígena y que esta es una consecuencia directa de la cercanía espacial que existe entre la Colonia y las ciudades de Machagai y Quitilipi, que «contaminan» las costumbres indígenas. Como ya se ha dicho, para fomentar que los niños se familiaricen con la lengua indígena, al iniciar el momento del desayuno (cada curso desayuna en su aula) realizan un canto de agradecimiento y bendición en lengua qom. Además, las clases son impartidas en español; los niños solo tienen una materia destinada exclusivamente al aprendizaje de la lengua indígena (a la cual dedican una hora todos los días). Ese es el único momento en que los estudiantes leen y escriben en qom. Dentro de la escuela, ellos interactúan en español, solo unos pocos emplean el qom para comunicarse. Desde el seno escolar insisten con conservar la tradición oral, pero esto representa todo un desafío ya que los chicos prefieren, por ejemplo, más la música criolla que la de ellos.

Un líder puntero político (quien tiene seis hijos) ha asegurado que tenemos como prioridad la educación de nuestros hijos porque tienen que ser alguien en la vida. Por eso, insistimos en hablar nuestra lengua con ellos, pero con las más chiquitos esto es difícil por la influencia. También, una docente de nivel inicial al pensar en la Educación Intercultural Bilingüe expresaba: a los chicos primero les

\footnotetext{
${ }^{2}$ Hay que decir que durante las entrevistas realizadas fueron pocos los casos en los que había niños presentes. De hecho, solo en uno los chicos que había hablaban fluidamente qom. No es un dato menor aclarar que estaban en la casa de su abuela.
} 
costaba, ahora ya se animan más, porque vienen desde la casa con el español incorporado. Los chicos no se aceptaban, recién ahora se empiezan a considerar aborígenes, se reconocen.

Finalmente, en el ámbito religioso el uso de la lengua indígena tiene un lugar particular, desde la lectura de la palabra hasta los cantos que entonan. Las celebraciones son bilingües.

Frente a lo observado puede hablarse de bilingüismo. En Colonia Aborigen se encuentran, por un lado, hablantes monolingües que hablan fluidamente la lengua indígena y, por otro, hablantes bilingües que tienen competencias tanto en la lengua vernácula como en el español. Dentro de esta última categoría se consideran aquellos hablantes bilingües competentes en la lengua vernácula, pero con baja competencia en español. Al igual que a aquellas personas que hablan $y$ entienden una de las lenguas pero que poseen una competencia receptiva en la otra, es decir, que la comprenden en mayor o menor medida, pero no la hablan con fluidez. Durante el trabajo de campo realizado hasta el momento ha sobresalido el bilingüismo receptivo de los niños y jóvenes indígenas que han aprendido el español como primera lengua. Ellos pueden comprender órdenes, palabras aisladas, frases frecuentes de la lengua de sus mayores, pero no hablarla fluidamente (Hecht y Messineo, 2007).

La categoría de bilingüe receptivo pone el acento en la competencia comunicativa, y no en la competencia lingüística. Este es un término interesante debido a que en la comunidad en cuestión la mayoría de los miembros no poseen fluidez ni manejo correcto de la gramática en la lengua indígena, pero son comunicativamente activos. También, están aquellos que pueden ser considerados como recordantes, son quienes pueden recordar palabras o frases en la lengua de sus padres o abuelos, pero no la utilizan como instrumento de comunicación ni la transmiten a sus hijos.

Igualmente, puede mencionarse un término acuñado por Hecht (2010) en el marco de su investigación de doctorado, al considerar la actitud activa y la agencia de los niños que tienen la capacidad para hablar qom pero, que pueden o no activarla. Es el caso de hablantes in(activos). 


\section{CONCLUSIONES}

En este artículo se ha presentado un panorama de la situación sociolingüística de la lengua qom en Colonia Aborigen Chaco. Dentro de las reflexiones y de las causas del desplazamiento de la lengua expresadas por los miembros de la comunidad entrevistados se identifican: la interrupción de la transmisión de generación en generación, la escolaridad, la negación de la lengua por vergüenza y discriminación, la necesidad de asimilarse a la sociedad mayoritaria (principalmente por trabajo y educación).

En los lotes visitados, algunas personas manifestaron el uso de la lengua vernácula en el ámbito familiar y en reuniones con amigos, como así también en las celebraciones religiosas y reuniones públicas. Otras, en cambio, emplean el español en casi todas sus interacciones. Por ello, puede decirse que dentro de los Lotes 38 y 39 conviven hablantes - y hablantes in(activos) qom-con hablantes bilingües receptivos y personas que solo hablan el español (las cuales son, en su mayoría, jóvenes y niños).

Frente a la situación expuesta los entrevistados consideran que es fundamental «buscar estrategias para llegarles a los chicos». Ven en ese grupo etario la principal necesidad para evitar el avance del proceso de desplazamiento. Al mismo tiempo, plantean la importancia de reflexionar sobre la EIB, ya que no responde a las necesidades lingüísticas de los miembros de la comunidad. Es decir, la escuela parece ser al mismo tiempo una amenaza y un motor para la revitalización lingüística. Esta es una observación importante a tener en cuenta para el progreso y futuro de la actual investigación, ya que tal como proponen Censabella y Gómez (2013), las acciones de revitalización deben estar en consonancia con las ideologías lingüísticas de sus destinatarios, de lo contrario están destinadas al fracaso. 


\section{REFERENCIAS BIBLIOGRÁFICAS}

Berruto, G. (1979). La Sociolingüística. Editorial Nueva Imagen, S.A. Sacramento 109, México 12, D.F.

Censabella, M. (2005). La revitalización de las lenguas y la educación bilingüe intercultural. Ponencia leída en el V Encuentro de Lenguas Aborígenes y Extranjeras, Dpto. de Lenguas Modernas. UNLP

Censabella, M., Gimenez, M. y Gómez, M. (2013). «Políticas lingüísticas recientes en la provincia de Chaco (Argentina) y su posible impacto en la revitalización de lenguas indígenas». Voces e imágenes de las lenguas en peligro. Quito: Abya Yala; 2013; pp. 319-327.

Duranti, A. (2000). Antropología lingüística. Madrid: Cambridge Univerisity Press. Recuperado de https://es.scribd.com/document/305489320/Duranti-Alessandro-Antropologia-Linguistica

Guber, R. (2001). Etnografía: Método, Campo y Reflexividad. Bogotá D.C: Grupo editorial Norma; 2001.

Hamel, R. (1995). «Conflictos entre lenguas y derechos lingüísticos: perspectivas de análisis sociolingüístico». Alteridades. Vol. 5, № 10. Universidad Autónoma Metropolitana Unidad Iztapalapa Distrito Federal, México; 1995, pp. 79-88. Recuperado de: http://www.redalyc.org/articulo.oa?id=74711345007

- (2003). «Conflicto entre lenguas, discursos y culturas en el México indígena: Los procesos de desplazamiento lingüístico». En Palavra, N 11, Río de Janeiro, pp. 63-88. Hecht, A.C. y Messineo, C. (2007). «Bilingüismo, socialización e identidad en comunidades indígenas». Anales de la educación común. Tercer siglo, año 3, № 6. Educación y lenguajes. Recuperado de http://servicios.abc.gov.ar/lainstitucion/revistacomponents/revista/archivos/anales/numero06/archivosparaimprimir/21_messineo_hecht_st.pdf

Hecht, A.C. (2009). Niñez y desplazamiento lingüístico: reflexiones acerca del papel del habla en la socialización de los niños tobas de Buenos Aires. Anthropologica/año 27, No 27; 2009, pp. 25-45.

(2010). «Todavía no se hallaron hablar en idioma» Procesos de socialización lingüística de los niños en el barrio toba de Derqui, Argentina. Lincom Studies in Sociolinguistics 09, Múnich: Lincom Europa Academic Publications. 
(2011). «Un análisis antropológico sobre la migración y el desplazamiento lingüístico entre hablantes de la lengua toba en Argentina». Gazeta de Antropología, 2011, 27 (1), artículo 14. Recuperado de http://hdl.handle.net/10481/15683 Messineo, C. (2003). Lengua toba (guaycurú). Aspectos gramaticales y discursivos. Lincom Studies in Native American Linguistics 48. Múnich: Lincom Europa Academic Publisher.

Romaine, S. (1996). El lenguaje en la sociedad. Una introducción a la sociolingüística. Ariel: Barcelona; 1996. 